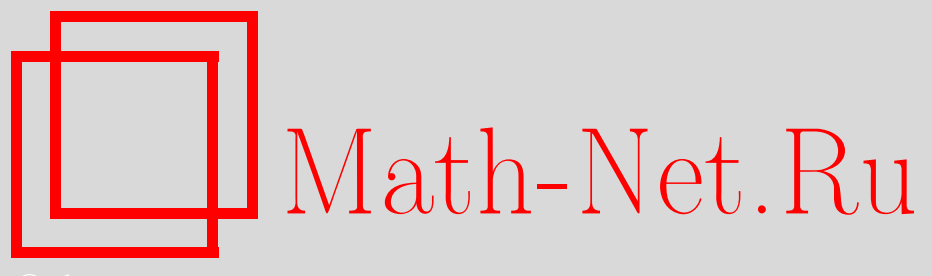

J. A. Adell, A. Lekuona, Estimates for moduli of smoothness of distribution functions, Теория вероятн. и ее примен., 2007, том 52, выпуск 1, 186-190

DOI: https://doi.org/10.4213/tvp14

Использование Общероссийского математического портала Math-Net.Ru подразумевает, что вы прочитали и согласны с пользовательским соглашением

http: //www . mathnet.ru/rus/agreement

Параметры загрузки:

IP : 54.197 .217 .227

26 апреля 2023 г., 18:27:57

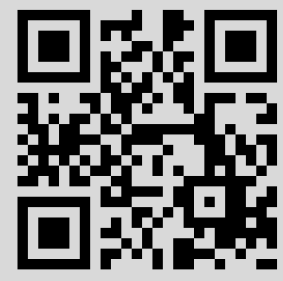


(c) $2007 \mathrm{r}$.

ADELL J.A.*, LEKUONA A.*

\title{
ESTIMATES FOR MODULI OF SMOOTHNESS OF DISTRIBUTION FUNCTIONS ${ }^{1)}$
}

\begin{abstract}
Приводятся верхние границы для обычных модулей гладкости функции распределения $F$ в терминах ее характеристической функции $\varphi$. В частности, мы дополняем некоторые известные оценки для функции концентрации, отвечающей $F$.

Наш подход использует новую версию классического неравенства сглаживания Бэрри-Эссена.
\end{abstract}

Ключевые слова и фразы: модуль гладкости, функция концентрации, характеристическая функция, неравенство сглаживания.

1. Introduction and main result. Throughout this note, we shall consider complex-valued measurable functions $f$ defined on $\mathbf{R}$, the supremum-norm of which is denoted by $\|f\|$. Let $m=1,2, \ldots$. The symmetric differences of $f$ with step $h \geqslant 0$ are recursively defined by

$$
\Delta_{h}^{1} f(x):=f\left(x+\frac{h}{2}\right)--f\left(x-\frac{h}{2}\right), \quad \Delta_{h}^{m+1} f(x):=\Delta_{h}^{1}\left(\Delta_{h}^{m} f\right)(x), \quad x \in \mathbf{R},
$$

or, equivalently, by

$$
\Delta_{h}^{m} f(x):=\sum_{k=0}^{m}(-1)^{k}\left(\begin{array}{c}
m \\
k
\end{array}\right) f\left(x+\left(\frac{m}{2}-k\right) h\right), \quad x \in \mathbf{R} .
$$

If $f$ is $m$ times differentiable, we have the following probabilistic interpretation (cf. [3]):

$$
\Delta_{h}^{m} f(x)=h^{m} \mathbf{E} f^{(m)}\left(x+\frac{h}{2} S_{m}\right), \quad x \in \mathbf{R},
$$

where $S_{m}:=U_{1}+\cdots+U_{m}$ and $\left(U_{i}\right)_{i \geqslant 1}$ is a sequence of independent identically distributed random variables having the uniform distribution on $[-1,1]$. Finally, the usual $m$ th modulus of smoothness of $f$ at length $\lambda \geqslant 0$ is defined by

$$
w_{m}(f ; \lambda):=\sup \left\{\left|\Delta_{h}^{m} f(x)\right|: x \in \mathbf{R}, 0 \leqslant h \leqslant \lambda\right\} .
$$

Let $X$ be a random variable with distribution function $F$ and characteristic function $\varphi$. The main result of this note is the following.

Theorem 1.1. For any $\lambda \geqslant 0, \varepsilon>0$, and $m=1,2, \ldots$, we have

$$
w_{m}(F ; \lambda) \leqslant \frac{\lambda^{m}}{2 \pi} \int_{|t| \leqslant 1 / \varepsilon}\left|t^{m-1} \varphi(t)\right| d t+2^{m} \varepsilon \int_{|t| \leqslant 1 / \varepsilon}|\varphi(t)| d t .
$$

$\mathrm{R} \mathrm{e} \mathrm{m}$ a r $\mathrm{k}$ 1.1. The constant $2^{m}$ in front of the second term on the right-hand side in (1.3) may be replaced by $2^{m} \cdot 6,1144 /(2 \pi)$, as follows from (2.8) below. On the other hand, letting $\varepsilon \rightarrow 0$ in (1.3), we see that

$$
w_{m}(F ; \lambda) \leqslant \frac{\lambda^{m}}{2 \pi} \int_{\mathbf{R}}\left|t^{m-1} \varphi(t)\right| d t
$$

whenever the preceding integral is finite.

* Departamento de Métodos Estadísticos, Edificio de Matemáticas, Universidad de Zaragoza, Pedro Cerbuna, 12, 50009 Zaragoza, Spain; e-mail: adell@unizar.es; lekuona@unizar.es

1) This work has been supported by research grants BFM2002-04163-C02-01 and DGA E-12/25, and by FEDER funds. 
Symmetric differences, as particular cases of divided differences, are widely used in diverse branches of applied mathematics (see, for instance, [3], [6] and the references therein). Moduli of smoothness, in particular weighted Ditzian-Totik moduli of smoothness of second order, characterize the rate of convergence in approximating a function $f$ by a sequence $\left(P_{n} f\right)_{n \geqslant 1}$, where each $P_{n}$ is a positive linear operator (cf. [2] and [8]).

The estimates concerning the first and second modulus of smoothness of a distribution function $F$ are of special interest for us. To this respect, observe that, due to the monotonicity of $F$, we can write

$$
w_{1}(F ; \lambda)=\sup _{x \in \mathbf{R}}(F(x+\lambda)-F(x)) \leqslant \sup _{x \in \mathbf{R}} \mathbf{P}\{x \leqslant X \leqslant x+\lambda\}=: Q(X ; \lambda),
$$

where $Q(X ; \lambda)$ is the concentration function of $F$ (cf. [10, p. 22]). There are papers, however, where $Q(X ; \lambda)$ is defined just as $w_{1}(F ; \lambda)$ (see, for instance, [7] and [12]). Estimates of the concentration function in terms of the characteristic function of $X$ go back to [9]. In this sense, consider the probability density $\rho(x)$ defined in (2.3) below and let $b>0$ be such that $\rho(x)$ decreases in $[0, b / 2]$. Let $\lambda>0$ and $\varepsilon>0$. Following the lines of the proof of Lemma 1.13 in [10], it can be verified that

$$
w_{1}(F ; \lambda) \leqslant \frac{\max \left(\varepsilon, \lambda b^{-1}\right)}{2 \pi \rho\left(\frac{1}{2} \min \left(\lambda \varepsilon^{-1}, b\right)\right)} \int_{|t| \leqslant 1 / \varepsilon}|\varphi(t)| d t .
$$

We refer to [11] for other estimates of this kind. On the other hand, we have from Theorem 1.1 that

$$
w_{1}(F ; \lambda) \leqslant\left(\frac{\lambda}{2 \pi}+2 \varepsilon\right) \int_{|t| \leqslant 1 / \varepsilon}|\varphi(t)| d t .
$$

None of the preceding estimates is uniformly better than the other. Indeed, if the characteristic function $\varphi$ is absolutely integrable, we arrive after letting $\varepsilon \rightarrow 0$ in (1.6) and (1.7) at

$$
w_{1}(F ; \lambda) \leqslant \frac{\lambda}{2 \pi b \rho(b / 2)} \int_{\mathbf{R}}|\varphi(t)| d t \quad \text { and } \quad w_{1}(F ; \lambda) \leqslant \frac{\lambda}{2 \pi} \int_{\mathbf{R}}|\varphi(t)| d t,
$$

respectively. Since

$$
\sup \left\{b \rho\left(\frac{b}{2}\right): b>0, \rho(x) \text { decreases in }\left[0, \frac{b}{2}\right]\right\}<\frac{1}{2}
$$

this means that (1.7) produces better estimates than (1.6) in this case. If, on the contrary, $\varphi$ is not absolutely integrable, we have the following. Estimate (1.6) is better than (1.7) for small values of $\lambda$. Actually, letting $\lambda \rightarrow 0$ in (1.6) and taking into account that $\rho(0)=1 /(2 \pi)$, we obtain (see also [11]) that

$$
\sup _{x \in \mathbf{R}} \mathbf{P}\{X=x\} \leqslant \varepsilon \int_{|t| \leqslant 1 / \varepsilon}|\varphi(t)| d t,
$$

while letting $\lambda \rightarrow 0$ in (1.7), we get twice the upper bound in (1.8). Nevertheless, if $\lambda$ is moderately large in comparison with $\varepsilon$, then (1.7) gives better estimates than (1.6). In any case, we can combine both (1.6) and (1.7) in order to obtain the following.

Corollary 1.1. Let $\rho(x)$ be as in (2.3) and let $b>0$ be such that $\rho(x)$ is decreasing in $[0, b / 2]$. For any $y \geqslant 0$ and $\varepsilon>0$, we have

$$
w_{1}(F ; \varepsilon y) \leqslant \frac{\varepsilon}{2 \pi} l_{b}(y) \int_{|t| \leqslant 1 / \varepsilon}|\varphi(t)| d t
$$

where

$$
l_{b}(y):=\min \left(y+4 \pi, \frac{1}{\rho(y / 2)} 1_{[0, b]}(y)+\frac{y}{b \rho(b / 2)} 1_{(b, \infty)}(y)\right), \quad y \geqslant 0,
$$

and $1_{A}$ stands for the indicator function of the set $A$. 
The estimate given in Corollary 1.1 is useful in dealing with rates of convergence in the central limit theorem, specifically, if we are interested in providing the main term of the approximation with a small constant (cf. [1]).

On the other hand, if $F$ is continuous, then $w_{2}(F ; \cdot)$ measures the speed of convergence in certain inversion formulas for the characteristic function $\varphi$ of $F$. In fact, let $N$ be a symmetric random variable and consider the approximants

$$
L_{t} F(x):=\mathbf{E} F\left(x+\frac{N}{t}\right), \quad t>0, \quad x \in \mathbf{R} .
$$

As shown in [2], some well-known inversion formulas for $\varphi$ may be simply translated into

$$
\lim _{t \rightarrow \infty} L_{t} F(x)=F(x), \quad x \in \mathbf{R} .
$$

If, in addition, $N$ satisfies good moment properties, for instance, if $N$ is the standard normal random variable, then

$$
c_{1} w_{2}\left(F ; \frac{1}{t}\right) \leqslant\left\|L_{t} F-F\right\| \leqslant c_{2} w_{2}\left(F ; \frac{1}{t}\right), \quad t>0,
$$

where $c_{1}$ and $c_{2}$ are explicit positive constants. Therefore, estimates of $w_{2}(F ; \cdot)$ are useful in establishing rates of convergence in the aforementioned inversion formulas.

Generally speaking, the two terms on the right-hand side in (1.3) have different meanings. If the distribution function $F$ is smooth, that is, if its associated characteristic function $\varphi$ satisfies nice integrability properties, then the order of convergence of $w_{m}(F ; \lambda)$ as $\lambda \rightarrow 0$ improves as $m$ increases. This is shown in (1.4) and is reflected by the first term on the upper bound in (1.3). If, otherwise, $F$ is not smooth enough, for instance, if $F$ has some discontinuities, then the use of $w_{m}(F ; \lambda)$ for $m=2,3, \ldots$, instead of $w_{1}(F ; \lambda)$ does not result in any improvement of the order of convergence, because any $w_{m}(F ; \lambda)$ involves the discontinuities of $F$. This is reflected by the second term on the upper bound in (1.3).

We finally point out that the proof of Theorem 1.1 is based on the version of the classical Berry-Esseen smoothing inequality contained in Lemma 2.2 in what follows. This is not surprising because, as follows from $(1.5), w_{1}(F ; \lambda)$ may be viewed as the Kolmogorov distance between the random variables $X-\lambda$ and $X$.

2. Proof of Theorem 1.1. Although inequality (1.4) was obtained as a consequence of Theorem 1.1, such an inequality is actually needed to prove this theorem. We therefore start with the following.

Lemma 2.1. For any $m=1,2, \ldots$ and $\lambda \geqslant 0$, we have

$$
w_{m}(F ; \lambda) \leqslant \frac{\lambda^{m}}{2 \pi} \int_{\mathbf{R}}\left|t^{m-1} \varphi(t)\right| d t,
$$

provided that the preceding integral is finite.

$\mathrm{P} \mathrm{r}$ o o f. By assumption and Theorem 1.6 in [10], $F$ is $m$ times differentiable and

$$
F^{(m)}(x)=\frac{(-i)^{m-1}}{2 \pi} \int_{\mathbf{R}} e^{-i t x} t^{m-1} \varphi(t) d t, \quad x \in \mathbf{R} .
$$

Therefore, the conclusion follows from (1.2).

Let $Y$ be a symmetric random variable independent of $X$. For any $\varepsilon \geqslant 0$, we consider the positive linear operator $P_{\varepsilon}$ acting on bounded functions $f$ and defined as

$$
P_{\varepsilon} f(x):=\mathbf{E} f(x+\varepsilon Y), \quad x \in \mathbf{R} .
$$

Observe that $P_{\varepsilon} F$ is the distribution function of the random variable $X+\varepsilon Y$. We give the following version of the classical Berry-Esseen smoothing inequality. Other smoothing inequalities can be found in [4, Chap. III, §1, p. 66-67] and [5, Lemma 10].

Lemma 2.2. Let $f$ and $g$ be two bounded functions such that $f$ is nondecreasing. Let $r>0$ be such that $p(r):=\mathbf{P}\{|Y| \leqslant r\}>\frac{1}{2}$. For any $\varepsilon>0$, we have

$$
(2 p(r)-1)\|f-g\| \leqslant\left\|P_{\varepsilon} f-P_{\varepsilon} g\right\|+\mathbf{E} w_{1}(g ; \varepsilon(r+Y)) 1_{\{|Y| \leqslant r\}} .
$$


P r o of. Let $x \in \mathbf{R}$. We use the notation $B:=[-r, r]$ and $H:=f-g$. By the monotonicity of $f$, we have

$$
\begin{aligned}
p(r) H(x) \leqslant & \mathbf{E}(f(x+\varepsilon(r+Y))-g(x)) 1_{B}(Y) \\
= & P_{\varepsilon} H(x+\varepsilon r)-\mathbf{E} H(x+\varepsilon(r+Y)) 1_{\mathbf{R} \backslash B}(Y) \\
& +\mathbf{E}(g(x+\varepsilon(r+Y))-g(x)) 1_{B}(Y) .
\end{aligned}
$$

Similarly, by the monotonicity of $f$ and the symmetry of $Y$, the converse inequality to $(2.2)$ holds replacing $\varepsilon$ by $-\varepsilon$. Thus, Lemma 2.2 follows from (2.2).

Henceforth, we consider the operator $P_{\varepsilon}$ defined in (2.1), where the random variable $Y$ has probability density $\rho(x)$ and characteristic function $\psi(t)$ given, respectively, by $\rho(x):=\frac{1}{2 \pi}\left(\frac{2}{x} \sin \left(\frac{x}{2}\right)\right)^{2}, \quad x \in \mathbf{R}, \quad$ and $\quad \psi(t):=\max (1-|t|, 0), \quad t \in \mathbf{R}$.

Lemma 2.3. For any $\varepsilon>0$, we have

$$
\left\|F-P_{\varepsilon} F\right\| \leqslant \varepsilon \int_{|t| \leqslant 1 / \varepsilon}|\varphi(t)| d t .
$$

$\mathrm{P}$ r o o f. Let $r>0$ be such that $p(r):=\mathbf{P}\{|Y| \leqslant r\}>\frac{1}{2}$. Applying Lemma 2.2 with $f=F$ and $g=P_{\varepsilon} F$, we obtain

$$
(2 p(r)-1)\left\|F-P_{\varepsilon} F\right\| \leqslant\left\|P_{\varepsilon} F-P_{\varepsilon}\left(P_{\varepsilon} F\right)\right\|+\mathbf{E} w_{1}\left(P_{\varepsilon} F ; \varepsilon(r+Y)\right) 1_{\{|Y| \leqslant r\}} .
$$

By Fourier inversion and (2.3), we have that

$$
\begin{aligned}
\left|P_{\varepsilon} F(x)-P_{\varepsilon}\left(P_{\varepsilon} F\right)(x)\right| & =\frac{1}{2 \pi}\left|\int_{|t| \leqslant 1 / \varepsilon} e^{-i t x} \varphi(t) \psi(\varepsilon t) \frac{1-\psi(\varepsilon t)}{i t} d t\right| \\
& \leqslant \frac{\varepsilon}{2 \pi} \int_{|t| \leqslant 1 / \varepsilon}|\varphi(t)| d t, \quad x \in \mathbf{R} .
\end{aligned}
$$

Applying Lemma 2.1 with $m=1$ and recalling (2.3), we have

$$
\begin{aligned}
\mathbf{E} w_{1}\left(P_{\varepsilon} F ; \varepsilon(r+Y)\right) 1_{\{|Y| \leqslant r\}} & \leqslant \frac{\varepsilon}{2 \pi} \mathbf{E}(r+Y) 1_{\{|Y| \leqslant r\}} \int_{|t| \leqslant 1 / \varepsilon}|\varphi(t)| d t \\
& =\frac{r p(r) \varepsilon}{2 \pi} \int_{|t| \leqslant 1 / \varepsilon}|\varphi(t)| d t
\end{aligned}
$$

where the last equality holds because $Y$ is symmetric. We conclude from $(2.4)-(2.6)$ that

$$
\left\|F-P_{\varepsilon} F\right\| \leqslant \frac{\varepsilon(1+r p(r))}{2 \pi(2 p(r)-1)} \int_{|t| \leqslant 1 / \varepsilon}|\varphi(t)| d t .
$$

Finally, it can be performed with MAPLE ${ }^{\circledR}$ that

$$
\min \left\{\frac{1+r p(r)}{2 p(r)-1}: r>0, p(r)>\frac{1}{2}\right\} \leqslant 6,1144
$$

The conclusion follows from (2.7) and (2.8).

$\mathrm{P}$ r o of of $\mathrm{T}$ h e o r e $\mathrm{m}$ 1.1. From (1.1) and Lemma 2.1, we have that $w_{m}(F ; \lambda) \leqslant w_{m}\left(P_{\varepsilon} F ; \lambda\right)+w_{m}\left(F-P_{\varepsilon} F ; \lambda\right) \leqslant \frac{\lambda^{m}}{2 \pi} \int_{|t| \leqslant 1 / \varepsilon}\left|t^{m-1} \varphi(t)\right| d t+2^{m}\left\|F-P_{\varepsilon} F\right\|$.

Thus, the conclusion follows from Lemma 2.3 . 


\title{
СПИСОК ЛИТЕРАТУРЫ
}

1. Adell J. A., Lekuona A. Berry-Esseen bounds for standardized subordinators via moduli of smoothness. - J. Theoret. Probab. (to appear).

2. Adell J. A., Sangüesa C. Real inversion formulas with rates of convergence. - Acta Math. Hungar., 2003, v. 100, № 4, p. 293-302.

3. Adell J. A., Sangüesa C. Approximation by $B$-spline convolution operators. A probabilistic approach. - J. Comput. Appl. Math., 2005, v. 174, № 1, p. 79-99.

4. Арак Т. В., Зайчев А.Ю., Равномерные предельные теоремы для сумм независимых случайных величин. - Тр. МИАН, 1988, т. 174, с. 1-214.

5. Bentkus V., Götze F., Paulauskas V. Bounds for the accuracy of Poissonian approximations of stable laws. - Stochastic Process. Appl., 1996, v. 65, № 1, p. 55-68.

6. DeVore R. A., Lorentz G. G. Constructive Approximation. Berlin: Springer-Verlag, 1993, 449 p. (Grundlehren Math. Wiss., v. 303.)

7. Deshouillers J.-M., Freiman G. A., Yudin A. A. On bounds for the concentration function, I. - Astérisque, 1999, v. 258, p. 425-436.

8. Ditzian Z., Totik V. Moduli of Smoothness. New York: Springer-Verlag, 1987, 227 p. (Springer Ser. Comput. Math., v. 9.)

9. Esseen C. G. On the Kolmogorov-Rogozin inequality for the concentration function. - Z. Wahrscheinlichkeitstheor. Verw. Geb., 1966, v. 5, p. 210-216.

10. Petrov V.V. Limit Theorems of Probability Theory. New York: Clarendon Press, 1995, 292 p. (Oxford Stud. Probab., v. 4.)

11. Салихов Н. П. Оценка функции концентрации методом Эссеена. - Теория вероятн. и ее примен., 1996 , т. 41 , в. 3, с. 561-577.

12. Stef A., Tenenbaum G. Inversion de Laplace effective. - Ann. Probab., 2001, v. 29, p. $558-575$.

Поступила в редакцию 22.XI.2004

(c) $2007 \mathrm{r}$.

$$
\begin{gathered}
\text { г. BUCKDAHN R.*, ENGELBERT H.-J.** } \\
\text { ON THE CONTINUITY OF WEAK SOLUTIONS OF } \\
\text { BACKWARD STOCHASTIC DIFFERENTIAL EQUATIONS }{ }^{1)}
\end{gathered}
$$

\begin{abstract}
В настоящей статье обсуждается понятие слабого решения общего обратного стохастического дифференциального уравнения (ОСДУ), введенное авторами и А. Рашкану в [2]. Изучена взаимосвязь между непрерывностью решений, потраекторной единственностью, единственностью по распределению и существованием потраекторно единственного сильного решения. Основной результат утверждает, что если все слабые решения ОСДУ непрерывны, то решение является потраекторно единственным. Следует отметить, что этот результат специфичен для ОСДУ и, разумеется, не имеет аналога в случае (прямых) стохастических дифференциальных уравнений. Как следствие, если существует
\end{abstract}

* Laboratoire des Mathématiques, Université de Bretagne Occidentale, F-29200 Brest, France; e-mail: Rainer.Buckdahn@univ-brest.fr

** Institut für Stochastik, Friedrich Schiller-Universität, D-07740 Jena, Germany; e-mail: engelbert@minet.uni-jena.de

1) The work was supported in part by the European Community's Human Potential Programme under contract HPRN-CT-2002-00281 (Evolution Equations). 